\title{
Faces in the Wilderness: a New Network of Crossdated Culturally-Modified Red Pine in the Boundary Waters Canoe Area Wilderness of Northern Minnesota, USA
}

\author{
Evan R. Larson ${ }^{1}$ (D) - Lane B. Johnson ${ }^{2} \cdot$ Thomas C. Wilding $^{3} \cdot$ Kalina M. Hildebrandt $^{4} \cdot$ Kurt F. Kipfmueller $^{5} \cdot$ \\ Lee R. Johnson ${ }^{6}$
}

Published online: 8 November 2019

(C) The Author(s) 2019

\begin{abstract}
New dates from culturally modified red pine rediscovered in the Boundary Waters Canoe Area Wilderness in northern Minnesota provide an opportunity to merge tree-ring records of human land use with archaeological records, historical travel accounts, and traditional knowledge to enhance understanding of Anishinaabeg land tenure in the Wilderness. Records from 244 culturally modified trees (CMTs) demonstrate varying intensities of human use along historical water routes, notably the Border Route that connected Grand Portage to Rainy Lake and Lake of the Woods during the North American fur trade. Crossdated modification years from 119 CMTs provide direct evidence of human-landscape interaction along historical travel routes utilized by Anishinaabeg and Euro-American traders from the mid-1700s to the early 1900s. This CMT network preserves a fading biological record of fur-trade-era cultural history that contributes to a growing cross-cultural conversation on the storied traditional use of a cultural landscape that is now the most visited federal wilderness area in the United States.
\end{abstract}

Keywords Culturally modified trees · Anishinaabe landuse $\cdot$ Fur trade $\cdot$ Minnesota, USA · Boundary Waters Canoe Crea Wilderness

\section{Introduction}

The wilderness concept is a powerful idea that shapes land conservation ethics and management options and decisions, and draws clear lines between people and nature (Vale 1998).

Evan R. Larson

larsonev@uwplatt.edu

1 Department of Geography, University of Wisconsin-Platteville, 261 Gardner Hall, 1 University Plaza Platteville WI 53818 USA

2 Research Forester, Cloquet Forestry Center, University of Minnesota, 175 University Road Cloquet MN 55720 USA

3 Geography/Geology Instructor, Nicolet Area Technical College, 5364 College Drive Rhinelander WI 54501 USA

4 Department of History, University of Wisconsin-Platteville, 1 University Plaza Platteville WI 53818 USA

5 Department of Geography, Environment, \& Society, University of Minnesota, 414 Social Sciences Building, 267-19th Avenue South Minneapolis MN 55455 USA

6 Forest Archaeologist \& Heritage Program Manager, USDA Forest Service, Superior National Forest, 8901 Grand Avenue Place Duluth MN 55808 USA
Increasingly, wilderness advocates are beginning to grapple with the reality that wilderness is also a western social construct (Cronon 1996) that diminishes the histories of Indigenous groups who continue to treat wilderness landscapes as important components of their current and past cultures and identities. The ecological legacies of Indigenous groups, who at times played highly influential roles in shaping historical vegetation patterns and disturbance processes (Stewart 2002), in present-day wilderness have been a topic of theoretical debate (Denevan 1992, 2011; Vale 2002) but remain an aspect of ecology that is underrepresented in the scientific literature. The failure to acknowledge Indigenous peoples as important agents in shaping the historical ecology of today's wilderness landscapes, and protected areas more generally, has resulted in hands-off management policies that adversely impact the resilience of ecological and social systems, particularly since establishment of the 1964 Wilderness Act. In federally-designated wilderness areas, tangible and intangible reminders of Indigenous land tenure, both physical artifacts as well as Indigenous histories, can help reframe western perspectives on wilderness landscapes and the relationship between people and the land.

Culturally modified trees (CMTs) are one type of biological artifact that can provide place-based and temporally-precise 
insight into historical Indigenous land use prior to the formation of present-day wilderness lands and protected natural areas (Östlund et al. 2005). Known purposes for the cultural modification of trees are myriad and include marking locations and property, indicating travel routes, extracting resources, or for ceremonial reasons (e.g., Turner et al. 2009). Each of these practices leaves a distinct mark on the modified tree that, in certain circumstances, can serve as a direct indicator of human activities that remain rooted to discrete locations and times (Östlund and Bergman 2006).

Networks of documented CMTs developed around the world have been used to examine historical, social, and economic responses to changing environmental, cultural, and technological conditions. Identification of the timing of these modifications through tree-ring analysis of the associated cambial scars has provided insight into periods of food scarcity, seasonal patterns of food gathering, historical travel routes, and periods of cultural change (e.g., Swetnam 1984; Mobley and Eldridge 1992; Zackrisson et al. 2000; Östlund et al. 2005; Morrison and Shepard 2013; Östlund et al. 2015; Samojlik et al. 2019).

Here, we report a new network of dendrochronologicallydated CMTs that spans the Boundary Waters Canoe Area Wilderness (BWCAW), a federally-designated wilderness reserve in the Border Lakes Region of central North America. In this project, we define CMTs as long-lived pine species with physical evidence of stem modification, likely for the harvest of resin to waterproof the seams of birch-bark canoes (Johnson et al. 2018) or other birch-bark objects. For the purposes of this study, long-lived trees used for other traditional purposes such as trail marking or storytelling are not discussed here (e.g., Harwood and Ruuska 2013). This project was feasible because the BWCAW supports some of the largest tracts of primary forest in eastern North America and has a cultural history that spans at least nine millennia (Heinselman 1996).

Johnson et al. (2018) reported the first absolutely-dated records of CMTs in the Border Lakes and linked culturallymodified red pine to canoe manufacturing and maintenance activities on a historical fur trade route. Expanding these findings, our work 1) documents the location, physical characteristics, timing, and landscape setting of CMTs across the BWCAW; 2) places this information in the shifting cultural context of the Border Lakes; and 3) provides site- and time-specific evidence of human activity to inform archaeological inquiry into the longstanding relationships between people and landscapes. Additionally, temporally- and spatially-precise evidence of historical human activities in a modern wilderness area serves as rich cultural context to aid interpretations of an extensive and growing fire history and forest age structure dataset being developed for the BWCAW and greater Border Lakes Region (Johnson and Kipfmueller 2016; Kipfmueller et al. 2017; Larson et al. 2017). Finally, and perhaps most importantly, the overarching goal of this work was to use records from tree-rings as a catalyst and nonhuman voice to promote cross-cultural conversations that reframe perspectives on wilderness management and improve shared decision making among wilderness land managers and Indigenous communities (Tengö et al. 2017; Berkes 2018).

\section{Study Site}

The Border Lakes Region is situated along the US-Canada border to the west of Lake Superior and includes three large conservation areas: Quetico Provincial Park in Ontario (476,000 ha), Voyagers National Park in Minnesota (88,000 ha), and BWCAW (441,000 ha), also in Minnesota and the focus of this study (Fig. 1a). This area of North America was repeatedly glaciated during the Pleistocene, with the resulting landscape a matrix of basalt and granite bedrock outcrops with thin soils and abundant island-studded lakes and rivers that created a network of waterways connecting Lake Superior to the interior of North America (Morse 1962). These waterways were fundamentally important for shaping the travel routes of human groups for millennia, and, particularly relevant to this work, the trade networks of the Great Lakes fur trade (Birk 1991).

Our research was conducted within the BWCAW, a federally protected wilderness area in the Superior National Forest of northern Minnesota, USA, created as part of the 1964 Wilderness Act (U.S. Congress 1964) and expanded and further defined by the 1978 Boundary Waters Canoe Area Wilderness Act (U.S. Congress 1978). Water is a defining feature of the BWCAW, with $20 \%$ of the protected area consisting of lakes and rivers connected by carrying points referred to as portages. Over 150,000 people visit the BWCAW annually as wilderness users. Travel within the wilderness is primarily by canoe, with visitors exhibiting strong preferences for island or peninsula campsites with open pine canopies on south and southwest facing slopes (Frissell and Duncan 1965) that provide an ideal combination of shade and sun, exposure to some breeze but protection from cooler north winds, and in many cases a chance of encountering blueberries in the summer months. Archaeological evidence suggests that humans have appreciated such sites for summer use for at least the past 2000 years (Johnson 2009). More generally, the vegetation communities in the region include a mosaic of boreal and temperate species (Heinselman 1973) and are broadly described as near-boreal (Frelich 2002).

Prior to its establishment as a wilderness area in the midtwentieth century, the BWCAW experienced human land use for millennia that was eventually influenced by global-scale geopolitical activities. Archaeological evidence outlines transitions from Clovis to Woodland traditions since the recession of the last glaciers around 9000 years ago (Mulholland et al. 1997). Ethnographic and oral histories indicate that both Siouan (Dakota and Assiniboine) and Algonquian (Cree) speaking indigenous groups occupied the area at the time of European contact in the 1600 s, after which control of the region transitioned to the Anishinaabeg (an Algonquian 

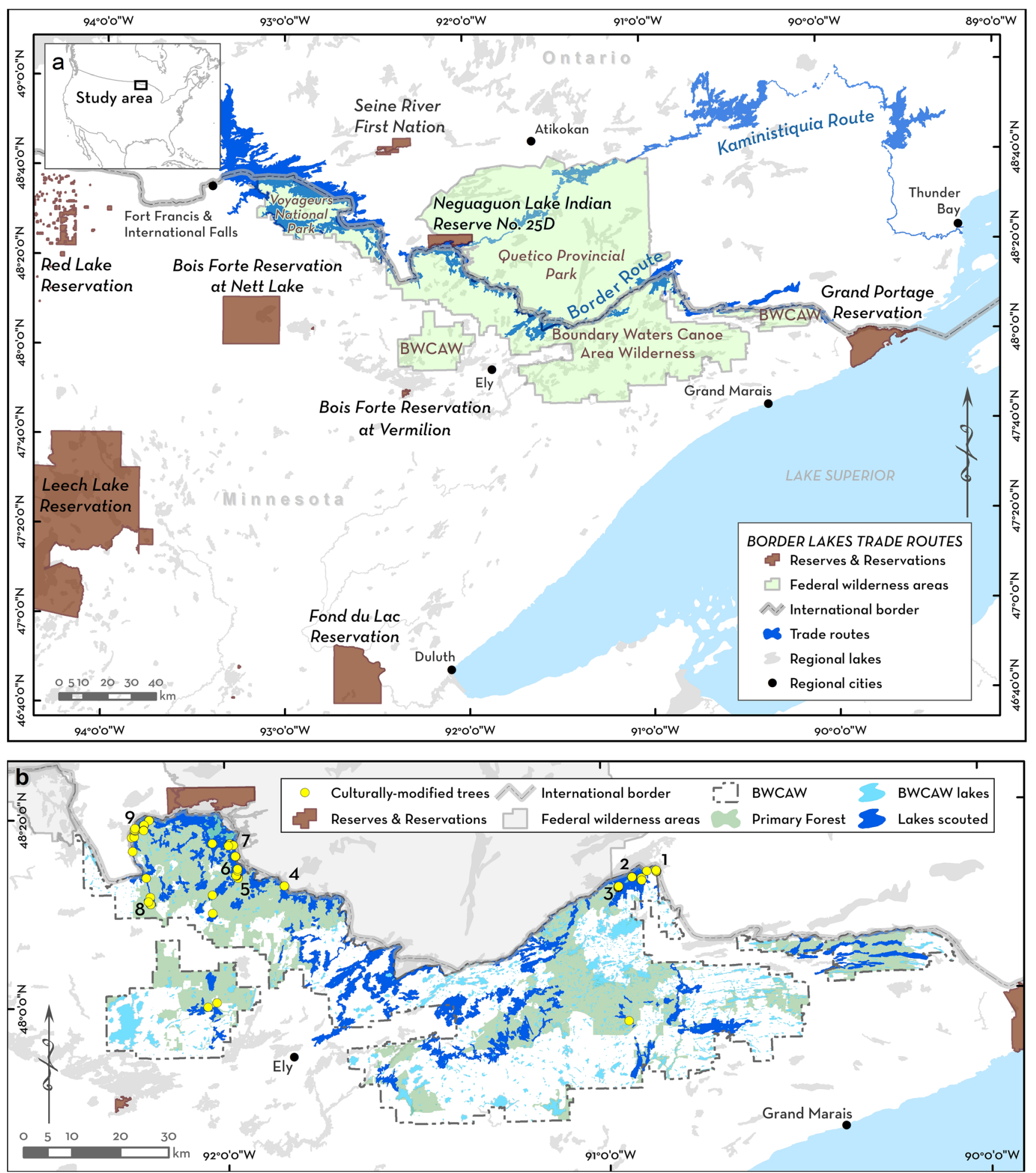

Fig. 1 Maps of the study area indicating: a the location of the Boundary Waters Canoe Area Wilderness (BWCAW) in the Border Lakes relative to First Nations Reserves (Canada) and Reservations (United States), federal wilderness areas, and historical trade corridors; $\mathbf{b}$ the location of documented culturally modified trees (CMTs) relative to shorelines of

speaking cultural group in the western Great Lakes region also referred to as Chippewa or Ojibwe, but who refer to themselves lakes within the BWCAW that were scouted for this research. Scouting focused on the remaining old-growth forest, shown in $\mathbf{b}$, which includes all lands that have no known history of disturbance from logging or severe fire over at least the last 120 years. Numbers on the map indicate clusters of CMTs and correspond to the sites specified in Fig. 6

as Anishinaabe (s) or Anishinaabeg (pl)) who established seasonal rounds of land use and subsistence resource utilization 
(Richner 2002; Warren 2009). The Anishinaabeg began interacting with European groups in the Border Lakes in the late 1600 s and early 1700 s, with a primary focus of these interactions from the 1780 s to 1840 s revolving around the fur trade (Morse 1969; Innis 1999). The extent of traditional land use since that time has been repeatedly constrained through a series of treaties and government actions intentionally crafted to disrupt traditional land use activities and culture (U.S. Congress 1854, 1887, 1889; Andrews 1900; Grover 2002).

Relationships between tribal groups and state and federal agencies since the early 1900s have been strained yet dynamic, with numerous community and legal efforts to recognize and regain treaty rights, address issues of sovereignty, advance economic development on reservation lands, and revitalize cultures impacted by two centuries of colonization and dispossession (Treuer 2010, Child 2014). Currently, seven Anishinaabe Bands are federally recognized in Minnesota. The Bois Forte Band of Chippewa, and the Grand Portage and Fond du Lac Bands of Lake Superior Chippewa are the geographically closest and have the most direct cultural connections to the lands of the BWCAW. The Lac La Croix First Nation community resides on Neguaguon Lake Indian Reserve 25D that directly adjoins the northern boundary of the study area (Fig. 1a).

\section{Methods}

\section{Field Methods}

The CMTs that are the focus of this research were first recognized while conducting a fire history study exploring the effects of traditional land use on fire regimes prior to the formation of the Superior National Forest in 1909. Numerous peeled trees were observed across the study area that, upon consultation with local oral histories, ethnographic and archaeological records, and the scientific literature, were realized to likely be related to the collection of resin, a key ingredient in the gum widely used to waterproof birchbark canoes, containers, and dwellings. Gum was an important provisioning good produced by Border Lakes Anishinaabeg during the fur trade (Johnson et al. 2018). Our assumption entering this work was that the CMTs of the BWCAW offered a spatially- and temporally-precise perspective on historical landuse during a dynamic period in the cultural and ecological history of the region. Upon realizing the potentially invaluable information that could be derived from documenting these unique cultural artifacts, meetings were held with tribal elders and knowledge keepers of the Bois Forte Band of Chippewa and Lac La Croix First Nation to discuss potential sampling procedures to ensure fieldwork for this project was conducted in a respectful manner. Fieldwork over the summers of 2015-2017 included scouting the shorelines of over 240 lakes by canoe and by foot, focusing specifically on areas within the remaining old growth forest of the BWCAW (Fig. 1b) (Johnson,
L.B., unpublished data). Peel scars were distinguished from other cambial injuries, such as fire, by their morphology and the common occurrence of tool marks on the peel face, and broadly classified as one of three categories based on shape and site: oblong, rectangular, or smaller test peels (Fig. 2). The term "test peel" is derived from the work of Thain White as discussed by Swetnam (1984) and refers to a small patch of bark peeled to determine the quality of the tree for the intended purpose.

All CMTs encountered were documented and georeferenced, and tree-ring samples were collected from dead trees and living trees that were sound enough to yield a viable sample with minimal disruption to the peel itself. Documentation of each CMT included the tree species, diameter at breast height, vitality (living, declining, or dead), number of peel scars and their dimensions, and physiographic setting including slope, aspect, azimuth to nearest shoreline, and distance to nearest shoreline. CMTs were subjectively classified as isolated or clustered, with isolated peels occurring singly and clusters representing two or more peeled trees that were located on a distinct landform such as an island, peninsula, or slope. Each peel scar face was photographed and its azimuth, current width at the widest point, current height from the lowest to highest point, height above ground of the lowest point, evidence of fire scarring, and the presence or absence of tool marks was recorded.

Increment core samples were collected from living CMTs, with multiple cores taken around each peel face to attempt to intersect the scar tip and obtain a sequence of rings from bark to pith to aid in crossdating the injury (Swetnam 1984). Cores were placed in paper straws and labeled for transport to the laboratory and sketches were made of the location of each core sample to aid interpretation of the resulting data. A handsaw or crosscut saw was used to collect cross sections from dead and down trees with well-preserved peels. Samples were labeled in the field, with attention given to indicating scars likely caused by human activities from those caused by fire, photographed, and wrapped in plastic wrap for transportation, via canoe and pack, out of the wilderness.

\section{Laboratory Methods}

All tree-ring samples were air dried. Fragile or broken cross sections were reassembled and glued onto plywood. Increment cores were glued into wooden core mounts prior to surfacing. All samples were sanded to a polished surface with progressively finer grit sand paper from 40 -grit to at least 400-grit (Stokes and Smiley 1996). The annual growth rings of each sample were analyzed under $3.5 \times-40 \times$ magnification and crossdated with reference chronologies previously developed for the BWCAW (Kipfmueller et al. 2010). Cambial injuries on the cross sections were identified as peel scars, fire scars, or other injuries based on field notes, photographs, and scar morphology relative to ring boundaries. Scar seasonality 

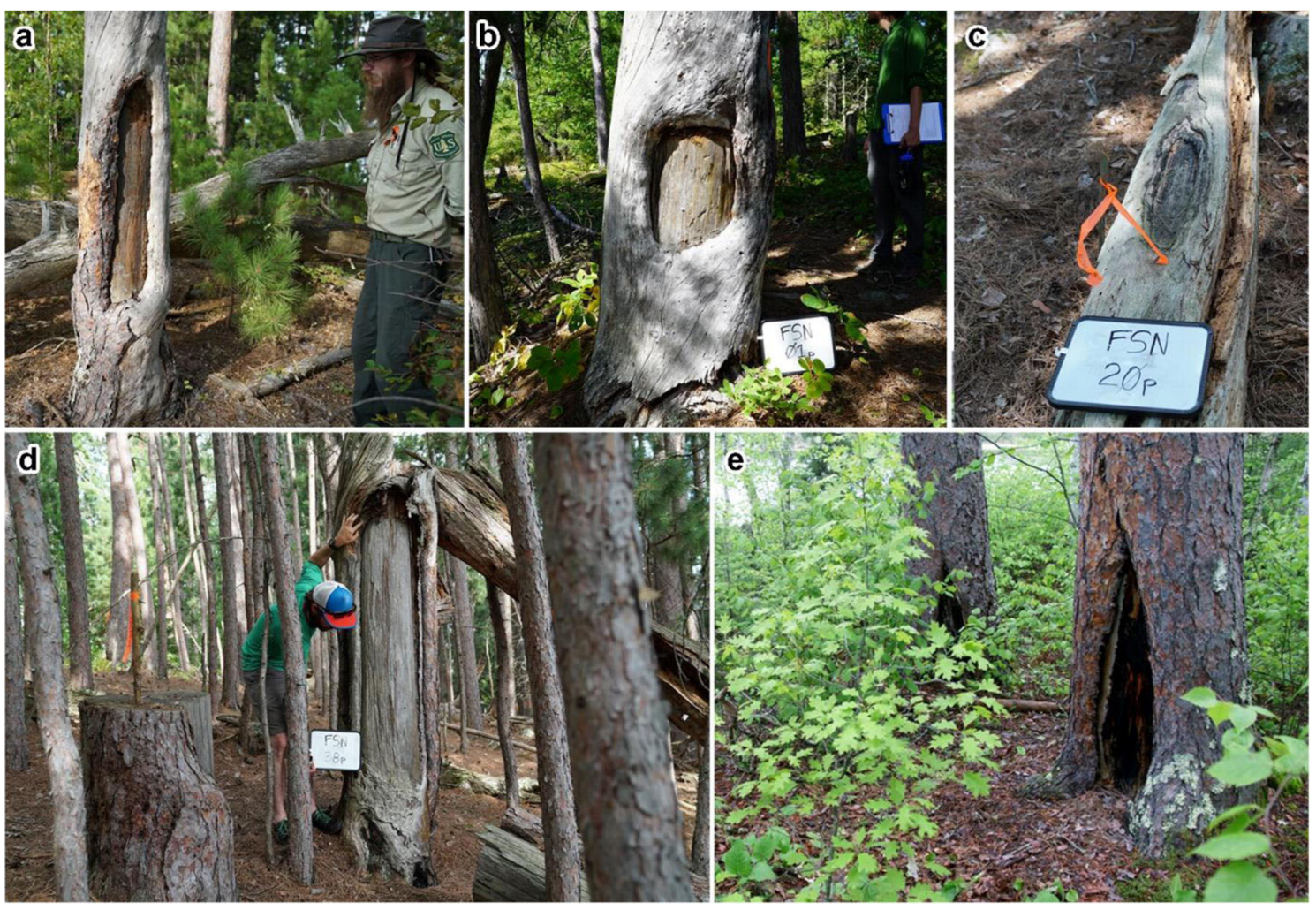

Fig. 2 Peel scar morphology was broadly categorized into three types: a oblong; b rectangular; c small/test peel. The area of rectangular peels varied greatly, as illustrated by the large peel in $\mathbf{d}$. A typical fire scar is shown in e for comparison and contrast. Key characteristics used to distinguish peel scars included the presence of tool marks on the peel face and the sweeping closure of the wound below the injury, which contrasted with the triangular shape of most fire scars that reach the ground. The small peel in c included multiple subsequent fire scars that occurred after the peel was created

approach in that it overestimated the surface area of peels that had irregular perimeters and underestimated the original peeled area due to the growth of healing lobes around the scar, but we felt this still captured variability in peel sizes despite underestimating peel dimensions at the time of modification. Landscape characteristics included distance to water, azimuth to the nearest shore, azimuth of the peel face, and azimuth of the peel face relative to the nearest shore. The overall area of use at each site with two or more CMTs was calculated as a minimum bounding convex hull based on the geographic coordinates of the CMTs at the site.

We examined the relationships among CMT characteristics and landscape position to determine if consistent relationships relating CMTs to specific cultural periods or areas of use existed. Maps were created to depict the spatial and temporal distribution of peel scars at sites with multiple CMTs. Distance to water, peel direction, and peel surface area were all related to peel date visually, as scatter plots, and statistically, through correlation analysis. Distributions of peel surface area and peel date were compared among peel shapes using 2-sample KolmogorovSmirnov tests to determine if specific types of peels were associated with specific time periods. 


\section{Cultural Resource Site Review}

Data on peel tree characteristics and locations were shared with Superior National Forest archaeologists, and spatial information was compared with a geospatial inventory of cultural resource sites within the BWCAW. The cultural resource spatial data for the BWCAW include approximately 3000 cultural resource sites identified during numerous survey events since the late 1970s. The working field hypothesis was that larger stands of peeled trees with multiple peeling events would likely be co-located with an archaeological component that was temporally and functionally supportive of the hypothesized purpose of the peel scars. In other words, we expected that artifacts of a similar age to the dated peel scars would be present within the stand, and that in many cases those artifacts would be related to the activity of resin collection and/or canoe building.

Based on a preliminary geospatial analysis, only two of the seven peel tree sites consisting of 10 trees or more had been previously surveyed for archaeological resources. These previously surveyed peel tree stands - Saga Island and Upper Pauness Lake - had data-rich archaeological sites within the stand boundaries identified during earlier archaeological survey efforts and included artifacts within the same date range of the peel scars themselves. During the course of the research reported here, the South Coleman Island site was selected as a likely candidate for further archaeological testing. The results of the South Coleman Island archaeological survey, which are summarized below, support the hypothesis guiding this work.

Commensurate with cultural resource site analysis, a preliminary historic records review was completed to gather primary source information that could shed light on past human use of the peel tree stands themselves or the adjacent travel routes. The records review included historic maps, fur-tradeera travel accounts, historical aerial photos, and oral histories. Four of the seven peel tree stands were found to have corroborating historical information that supported contemporaneous use of adjacent canoe routes, nearby habitation centers, and/or on-site or nearby canoe building locations.

The cultural resource site analysis, supporting archaeological survey, and associated historical records review have been fruitful avenues for building context for the peel trees and underscore the importance of multi-disciplinary approaches to human-landscape studies.

\section{Results}

\section{Peel Characteristics}

We documented 244 CMTs across the remaining old-growth forest of the BWCAW (Fig. 1b). The number of modifications on each CMT ranged from $1(77 \%)$ to $3(2 \%)$, with a total inventory of 305 unique peel scars. Most CMTs documented were dead $(n=178,73 \%)$ and ranged in state of decay from standing snags with bark to highly eroded remnants. A total of 227 peels were intact enough to categorize by shape, with $58 \%$ marked as oblong, $36 \%$ rectangular, and $6 \%$ small/test. Median peel dimensions based on 229 CMTs with sufficiently intact scar faces to measure were $13 \mathrm{~cm}$ wide (range: $1-63 \mathrm{~cm}$ ) by $71 \mathrm{~cm}$ tall (range: 10-205 $\mathrm{cm}$ ), with a median surface area of $938 \mathrm{~cm}^{2}$ (range: $40-7920 \mathrm{~cm}$ ), and median distance from the ground to the base of the peel scar of $55 \mathrm{~cm}$ (range: 0 $150 \mathrm{~cm}, n=219$ ) (Fig. 3). Peel height was more variable than peel width. An apparent threshold was evident in peel surface area, with $77 \%$ being $2000 \mathrm{~cm}^{2}$ or less. The median diameter at first modification was $20 \mathrm{~cm}$ (range: $7-32 \mathrm{~cm}, n=38$, Fig. $4 a$ ), while the median age of the tree at first modification was 70 years (range: $9-218$ years, $n=34$, Fig. 4b). Tool marks were present on the scar faces of 147 trees $(60 \%)$, and included chop marks along the top and bottom perimeter of the peel face (Fig. 5a), tool marks along the face that were possibly created when working the bark off of the tree (Fig. 5b), scratch marks potentially related to the removal of hardened resin from the peel scar (Fig. 5c), and in the case of two trees, knife marks along the peel perimeter where the bark was apparently cut away in a diamond-like pattern. Though not documented in the field, later discussion and reflection on a series of chopped fire-scar faces observed at several sites suggests that these, too, reflect intentional activities potentially related to the harvest of "fat wood," resinous heartwood used to start fires or possibly used for the collection of resin itself (Fig. 5d). These chopped trees were not included in any of the analyses reported here.

\section{Peel Dates and Seasonality}

We collected tree-ring samples from 141 CMTs (58\%), including increment cores from 64 trees and cross sections from 77 dead and downed trees. Unsampled trees were determined to be too rotten to acquire enough tree-ring material to crossdate the peel scars. We assigned absolute calendar dates to the rings of 119 CMTs (49\%). These samples contained 158 unique peel scars (52\%), 126 of which we dated precisely based on the intra-ring position of cambial scarring and 32 of which were dated within a 4-year window based on increment core samples. The earliest peel date identified in our samples was 1743 , with most peel scars dating to the 1700 s and 1800s (Fig. 6). Peaks in peel activity occurred in the 1770s and 1790s, synchronous with peak use of the Border Lakes route from Lake Superior to Rainy Lake by the Northwest Company (Nute 1941), while a distinct gap in peel activity occurred in our study area from 1802 to 1820 when the primary trade route shifted to the more northern Kaministiquia Route (Morse 1969). An additional peak in peel creation occurred in the 1840 s, with a near complete 
Fig. 3 Peel scar dimensions as documented during field campaigns from 2015 to 2017 shown as: a histograms of peel width ( $\mathrm{x}$ axis), peel height ( $\mathrm{y}$ axis), and a bubble plot of peel surface area (circles scaled to surface area; estimated from width and height); $\mathbf{b}$ a histogram of peel surface area estimations; c a histogram of the distance from the ground surface to the bottom of the peel scar
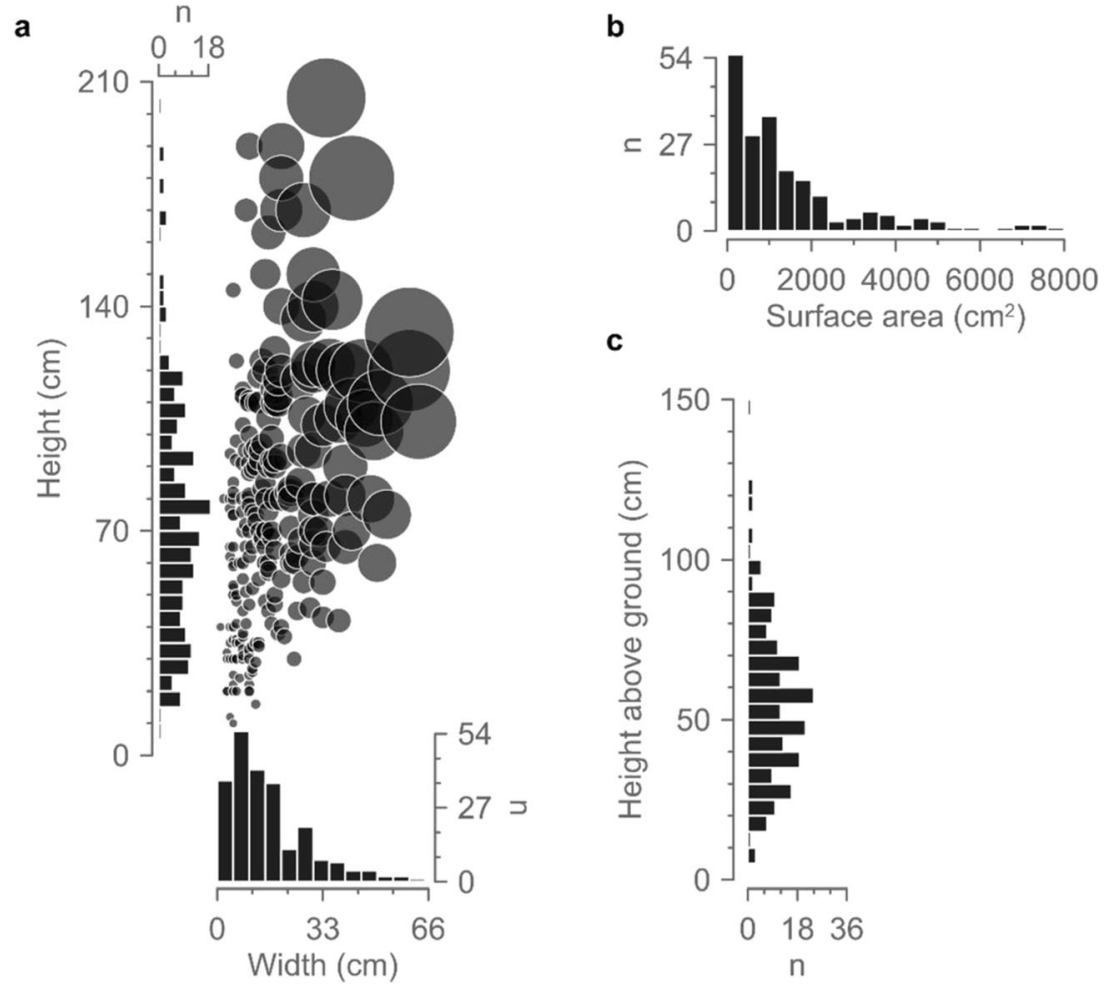

cessation of peel activity following the establishment of the Superior National Forest in 1909 (Roosevelt 1909). The most common peel scar position was in the early growing season $(65 \%)$, with occasional mid-season (16\%), late-season (10\%), and dormant season (9\%) peels. The accuracy of our increment core sampling approach was supported by a prior year ring of 1876 on a tree marked by General Land Office surveyors in 1877 , suggestive of the erosion of only a single growth ring since the tree was blazed (Fig. 7). We identified and dated 105 fire scars within the samples collected from peel trees, with a remarkable temporal association between fire and peel activity (Fig. 6).

\section{Landscape Characteristics}

We documented isolated CMTs at 31 locations, three sites with clusters of 2-9 CMTs, and seven sites with $\geq 10$ grouped CMTs. Most CMTs were located along the Border Route and
Fig. 4 Tree characteristics relative to the first peel scar including: a diameter; $\mathbf{b}$ age. Diameter at first peel is shown relative to overall tree diameter at breast height measured during fieldwork from 2015 to 2017. Tree age at first peel is shown as a histogram with 5-year age class bins, as well as individual points for each tree with quartiles shown as a box-and-whisker plot
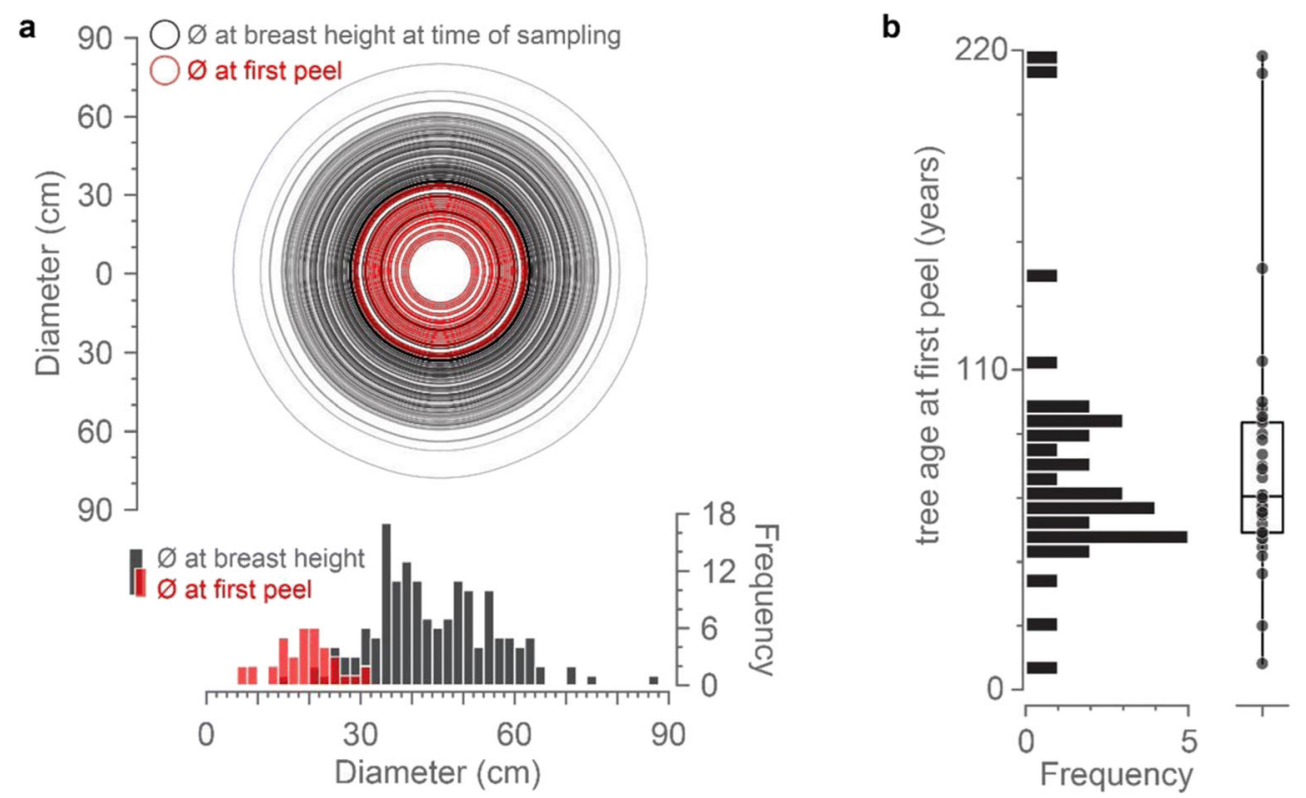

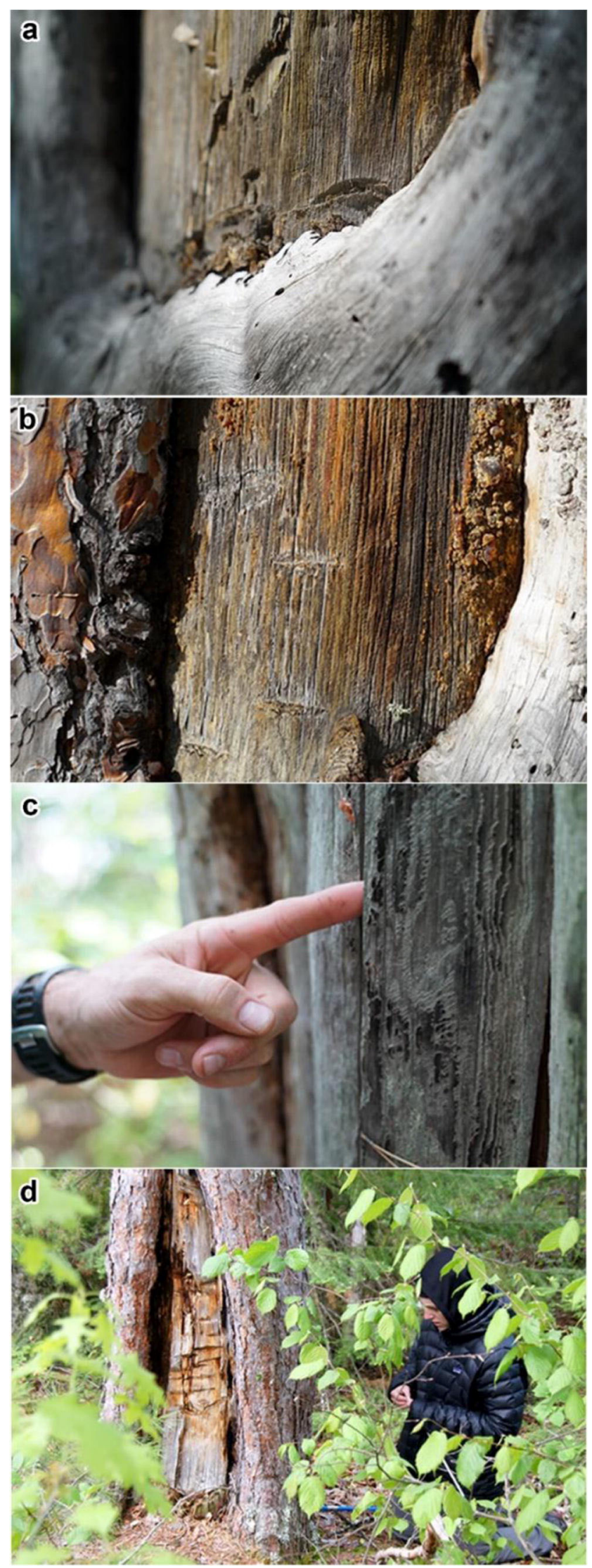

Fig. 5 Representative photographs of tool marks observed on the peel faces of culturally modified trees, including: a chop marks at the top and bottom of the peel face; $\mathbf{b}$ tool marks along the peel face, likely related to removal of the bark; $\mathbf{c}$ scratch marks possibly related to harvesting of hardened resin; $\mathbf{d}$ a chopped fire-scar face possibly related to the harvest of resin-impregnated "fatwood" for fire making but not quantitatively included in the inventory reported here

reflect areas closely associated with the fur trade, with a few notable exceptions including isolated peel trees at several offroute lakes and a cluster of 18 CMTs at Upper Pauness Lake (Fig. 1b). The majority of CMTs were located on south-facing shores (70\%), with most peels located on the north side of the scarred tree (54\%) (Fig. 8a). The difference in azimuth of peel relative to shoreline ranged from 0 to 180 , with a bimodal distribution of most trees either facing directly toward or away from the water (Fig. 8b). Sixty percent of CMTs were located within $10 \mathrm{~m}$ of water and $95 \%$ were located within $25 \mathrm{~m}$ (Fig. 8c), with large clusters of CMTs generally extending further from the lakeshore (Fig. 8d). The greatest concentration of peeled trees occurred on the south end of Coleman Island, eastern Lac La Croix, where 70 CMTs were documented within a single stand of old-growth red pine that occupied a southfacing slope overlooking a narrow stretch of water along the Border Route. Comparison of peel and landscape characteristics illustrated a mix of peel types and dates both within CMT clusters and among the locations where CMTs were documented (Fig. 9). Peel morphology was variable over the spatial and temporal extent of our study, with no relationship between the date of peel creation and any of the peel characteristics quantified in this study (Fig. 10).

\section{Discussion}

\section{Mapping Protohistoric Land Use in the Border Lakes}

The Border Lakes landscape is comprised of historically significant water-based travel corridors, overland trails between navigable waters, and stopping points along these water and land routes (Birk 1991). Many of the routes travelled by wilderness visitors today were established and used centuries prior to wilderness designation as part of a vast network of multi-cultural trade routes and Indigenous subsistence networks that allowed for efficient movement across the landscape in response to the change in seasonally available resources. It is possible that CMT records, compiled with treering-based fire records, offer evidence of a subtle yet discernable impact of Anishinaabeg use on the long-lived forest types of the Border Lakes (Johnson and Kipfmueller 2016; Larson et al. 2017). Just as Lewis and Ferguson described the maintenance of yards and corridors in a boreal forest mosaic (1988), the Border Lakes Anishinaabeg utilized their traditional lands in a way where cultural patterns of land use were 


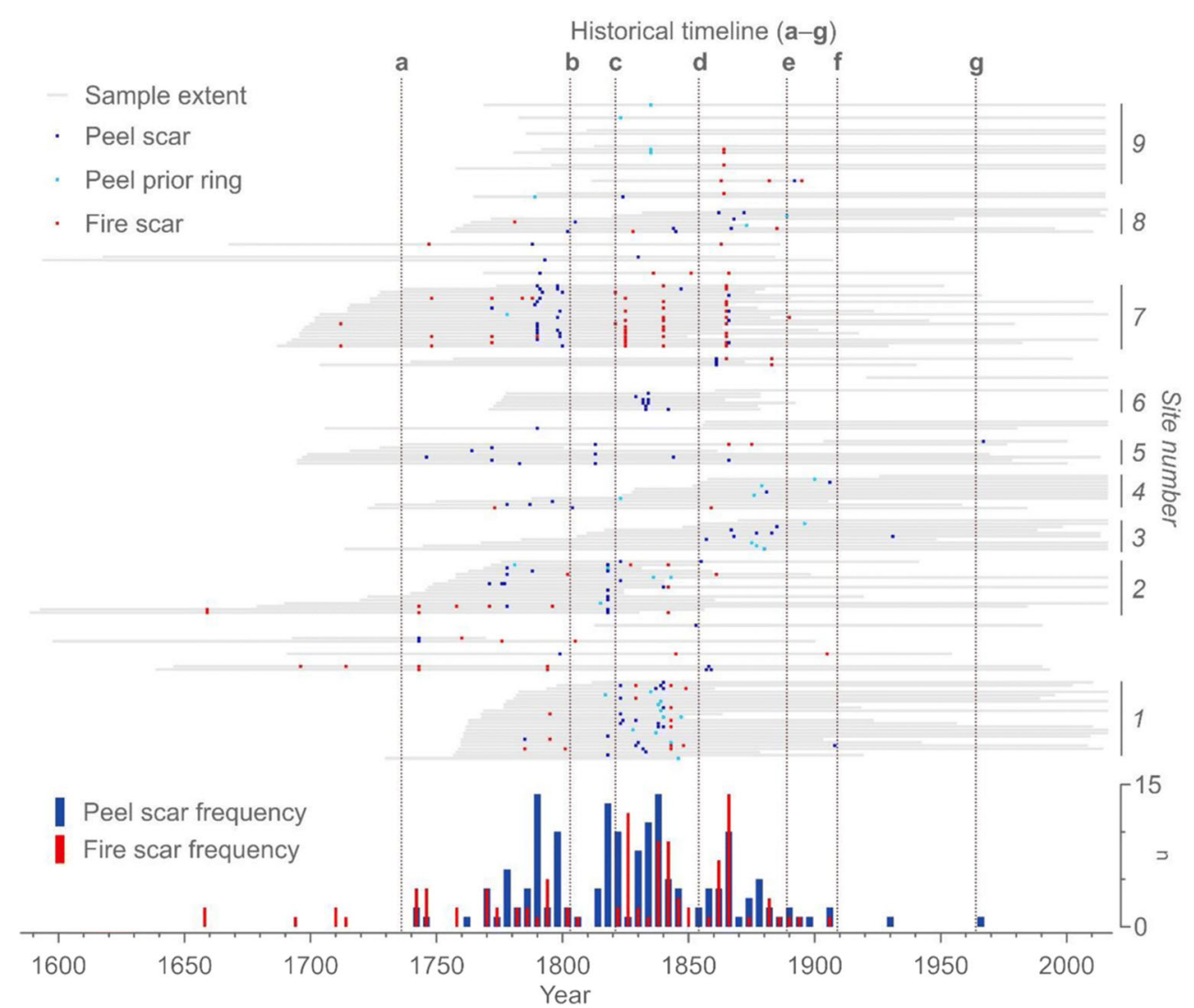

Fig. 6 Peel and fire scar chart depicting the occurrence of scars by sample (top) and as histograms (bottom). Numbered site locations marked on the right of the figure are listed east (1) to west (9) and correspond to numbered locations in Fig. 1b. Letters across the top indicate important points in time, including: a the first Anishinaabe settlement documented by European travelers along the western edge of the study area in 1736; b the shift of fur trade traffic from the study area along the Border Route north to the Kaministiquia Route following the relocation of trade activities from Grand Portage, Minnesota, to Fort William, Ontario, in 1802; c the merger of the Northwest Company and Hudson Bay Company in
1821 that resulted in the construction of trading posts along the Border Route and renewed canoe traffic; $\mathbf{d}$ the Treaty of 1854 that ceded lands including the study area to the U.S. government; e the Dawes Act of 1887 and the Nelson Act of 1889 that potentially pulled many Anishinaabeg away from the study area; $\mathbf{f}$ the establishment of the Superior National Forest in 1909; $\mathbf{g}$ the establishment of the BWCA in 1964. The histograms are shown with 4-year bins to summarize temporal changes in peel and fire scar occurrence and to match the minimum precision of prior ring dates of peel scars sampled with increment borers manifested on the physical landscape through the development of forest travel "corridors" and semi-domesticated forest "yards" manipulated by fire and maintained in an earlysuccessional state to promote plant species adapted to chronic disturbance (e.g., Vaccinium spp., Anderton 1999; Berkes and Davidson-Hunt 2006) and to create open forest structures and compositions that would have eased overland travel, created forage for game, reduced insect pests, and lowered highseverity fire risk to habitation sites. The location of single or small clusters of CMTs might be considered nodes along indiscrete water routes and large clusters of CMTs would be one type of utilized forest patch embedded in the historical forest mosaic. Over a century later, these patterns of traditional land use are sometimes detectable in the present forest mosaic but masked by changes in forest composition and structure following a century of retracted Anishinaabeg landuse, the absence of fire, and the accumulation of late-successional, fire-intolerant tree species in the understory. The network of CMTs described in this work can catalyze conversations about empowering traditional cultures and restoring a reciprocal relationship between people and the land (Kimmerer 2014). Understanding the character, distribution, and timing of these peels is a first step toward recognizing the agency exhibited in their creation.

Border Lakes CMTs are biological artifacts that help document the regional cultural landscape - the collection of storied places, forgotten and remembered, draped across the physical landscape - that speaks to past human-landscape interactions (Ryden 1993). The presence and distribution of CMTs provide direct connections between people and landscape in the Border Lakes and builds upon insights gained from the documentation of historical travel routes, traditional place names, pictographs, archaeological sites, and Anishinaabeg oral history to improve understanding of the 


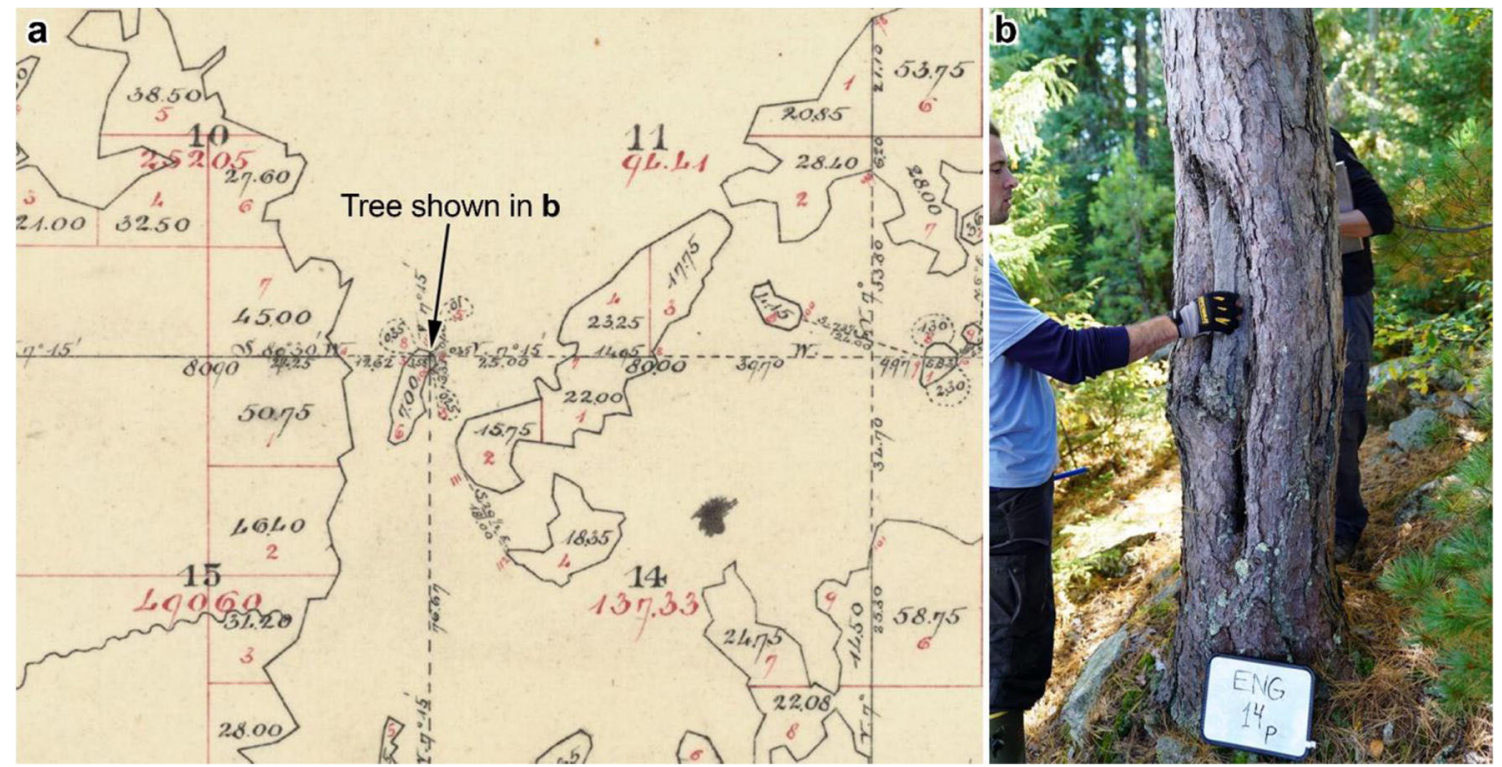

Fig. 7 Proof of concept for the accuracy of increment core-based dates for peel scars provided by: a General Land Office surveyor map indicating a corner tree marked on Englishman Island between September 1026,1877 ; $\mathbf{b}$ the tree in 2015 with a core-based modification date of 1876 . The difference of one year indicates the erosion of only a single growth

human ecology of the BWCAW prior to federal management and protection. The next steps for this work are to use these dates and data to engage in meaningful conversations regarding desired future conditions of federal wilderness areas that honor the long-standing and dynamic relationship between people, land, and place in the Border Lakes (Davidson-Hunt 2003). Such management could integrate perspectives drawn from multiple knowledge systems to incorporate the ecological and cultural legacies of the landscape in a way that empowers Indigenous communities while helping maintain a biologically diverse, resilient ecosystem (Díaz et al. 2015). In the BWCAW and other protected lands in the Border Lakes, this may entail developing prescribed fire programs based on traditional knowledge and an evolving concept of wilderness.

\section{Physical Setting and Peel Characteristics}

Patterns in the observed landscape setting of CMTs in the BWCAW suggest a strong relationship between the creation of peel scars and the physical landscape. The diversity in orientation, shape, and area of peel scars hint at a dynamic practice governed by various needs and intent that warrants deeper contemplation enriched with ethnographic and traditional knowledge. The consistency of culturally-modified red pine along south-facing lakeshores is a manifestation of shared site preferences for red pine and people. Red pine stands in the BWCAW are often found on dry, sunny south aspects of rocky peninsulas and islands due to red pine's ability to outcompete other tree species on these xeric, nutrient poor sites (Rudolf 1990). Individual red pine trees can persist ring since the tree was blazed. Survey notes of T66 R5W were accessed via the U.S. Department of the Interior Bureau of Land Management website (available: https://glorecords.blm.gov/default.aspx, accessed July 2, 2018)

up to 400 years in these sites despite exposure to high winds and occasional fires. These same warm and dry pine sites are often preferred campsite and picnic spots for wilderness users due to both their aesthetic qualities and practical appeal (Frissell and Duncan 1965). This mutual affinity for specific landform types, including well-drained islands and peninsulas, suggests that red pine forest types receive greater use by people relative to their abundance on the landscape, both today and in the past, due to both biotic (such as open red pine canopies and blueberry patches) and abiotic (such sunny, dry, warm, fire-prone) factors. Likewise, the presence of barkpeeled red pine within $25 \mathrm{~m}$ of shoreline at all but the largest sites is both due to increased survival of fire-resistant red pine at these locations in a high-severity fire environment (Heinselman 1973) and that shoreline red pine may be more practical trees from which to extract resin due to ease of access from the water. Previous ethnographies on Anishinaabe pitch use also mention that "trees growing near the water had the best gum" (Densmore 1929: 149).

The orientation of peel scar faces has previously been linked to ceremonial practices and in some cases orientation to the sun, as well as pragmatic reasons, such as the production of wood with specific traits or seeking inner bark with the most desired qualities (Östlund et al. 2002). The predominant north-northeast orientation of peel scar faces in the BWCAW seems likely to reflect practical reasons, as many of the trees were growing on south-southwest facing slopes and the peels were thus created on the uphill side of the tree where footing was more stable. Similarly, the height of most peels was variable but within a reasonable reach for most grown people. 


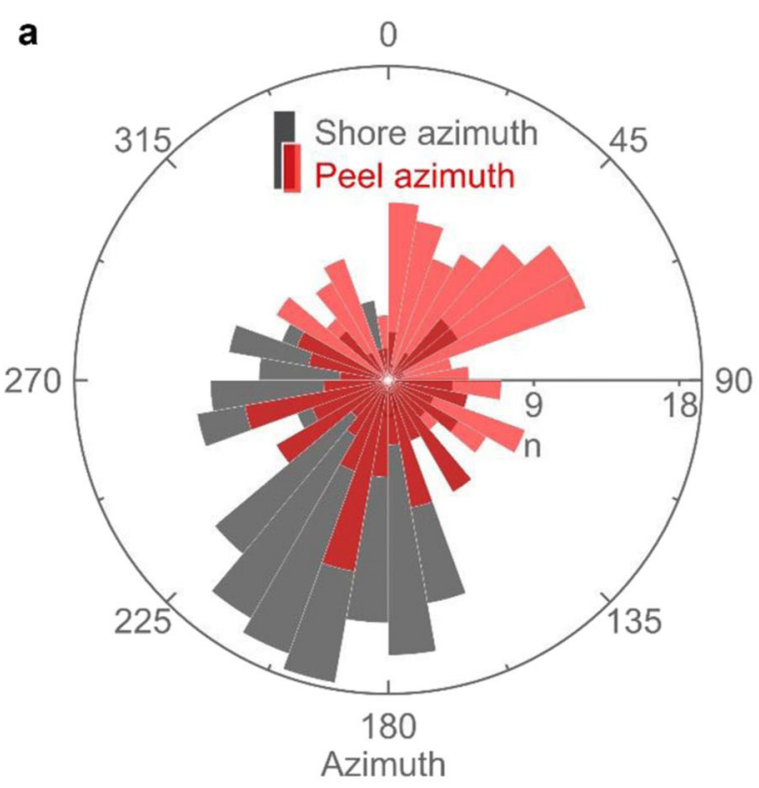

C

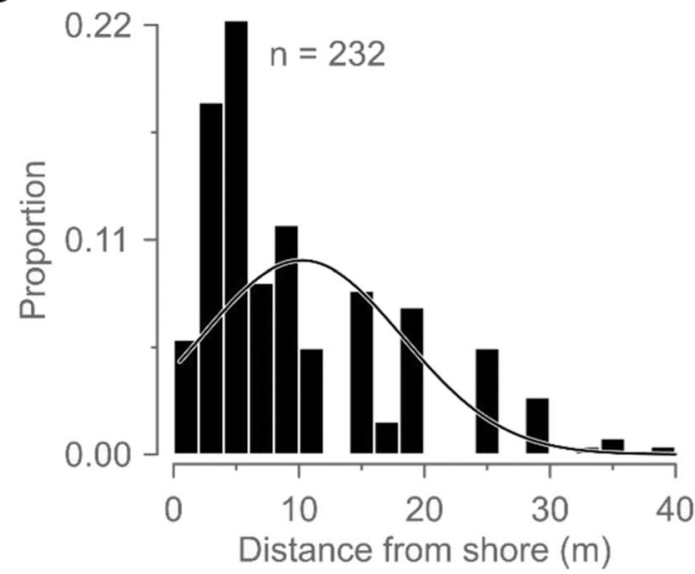

Fig. 8 Landscape characteristics of culturally-modified trees, including: a azimuth to the nearest shoreline and the azimuth of the peel scar faces; $\mathbf{b}$ difference between shoreline and peel azimuths; $\mathbf{c}$ distance from CMT to

The relatively small diameter and young age of trees in the year of peeling are similar to other studies (Zackrisson et al. 2000) and may reflect the availability of trees on the landscape following widespread and likely severe fire events in the study area ca. 1680 (Heinselman 1973), the stage of life when tree bark is most easily removed and the vigorous growth of young trees that produce the most resin, or that young peel trees are more likely to persist on the landscape to the present. The early growing season scar position of most peels in the BWCAW is also a shared trait with other CMT networks, and occurs during a time when bark slips most easily, trees are well hydrated, and pitch flows most readily (Zackrisson et al. 2000). The overall diversity and range in peel shape, size, and orientation, even at the scales of individual peel clusters, suggest that either the specific morphology of peels was not governed by strict practices (e.g., Bergman et al.
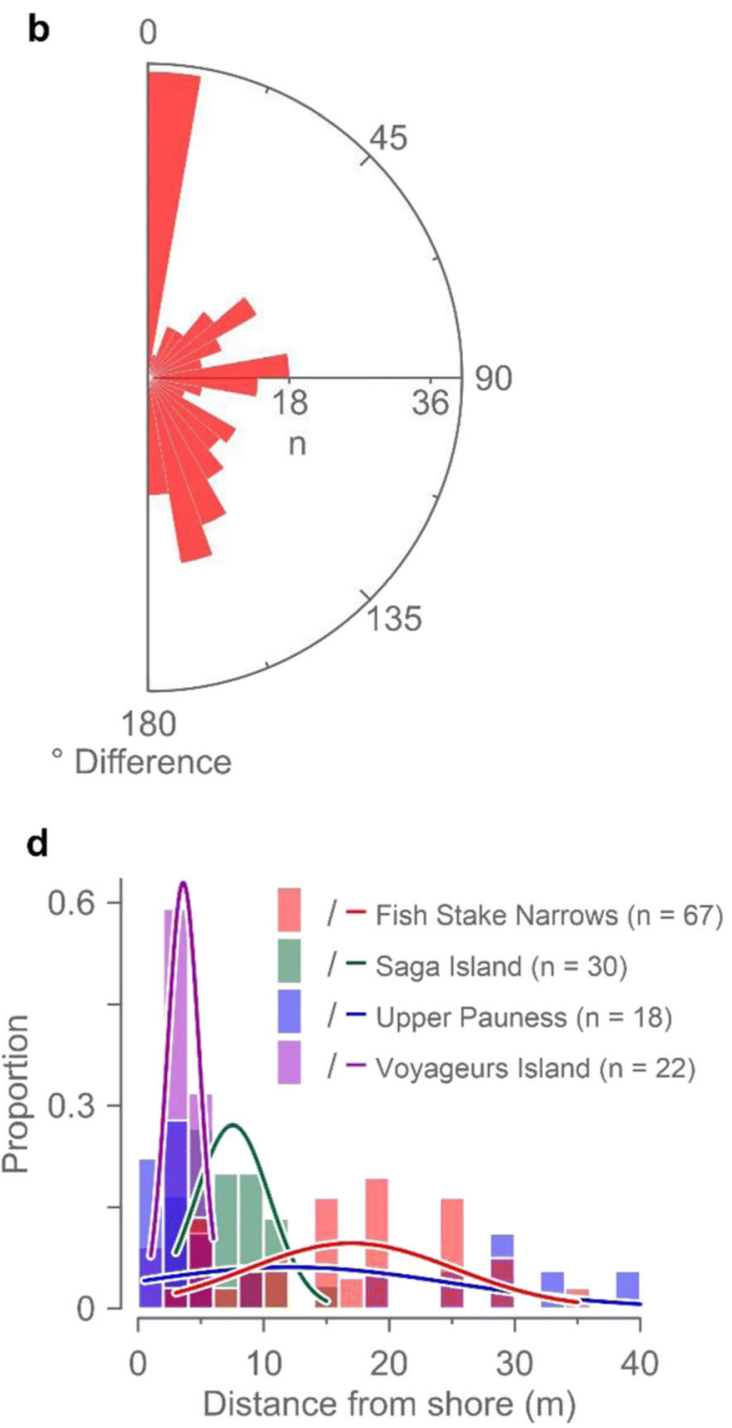

shoreline; $\mathbf{d}$ distance from CMT to shoreline for four clusters of CMTs to illustrate site-to-site differences

2004) or that the CMTs of the BWCAW represent a broader diversity of purposes and intent than resin collection alone. Additional ethnographic work and collaboration with Indigenous communities in the Border Lakes could help improve the understanding of the creation of these biological artifacts among managers and scientists so as to better advocate for their conservation and more thorough documentation (Östlund et al. 2002).

\section{Cultural Context for the Border Lakes CMT Network}

The earliest period of the CMT record is difficult to interpret definitively. No peels dated earlier than 1743 , yet the number of crossdated samples also declined rapidly prior to this time. Despite this limitation, the presence of peels and fire scars throughout the 1700 s and 1800 s aligned with a 

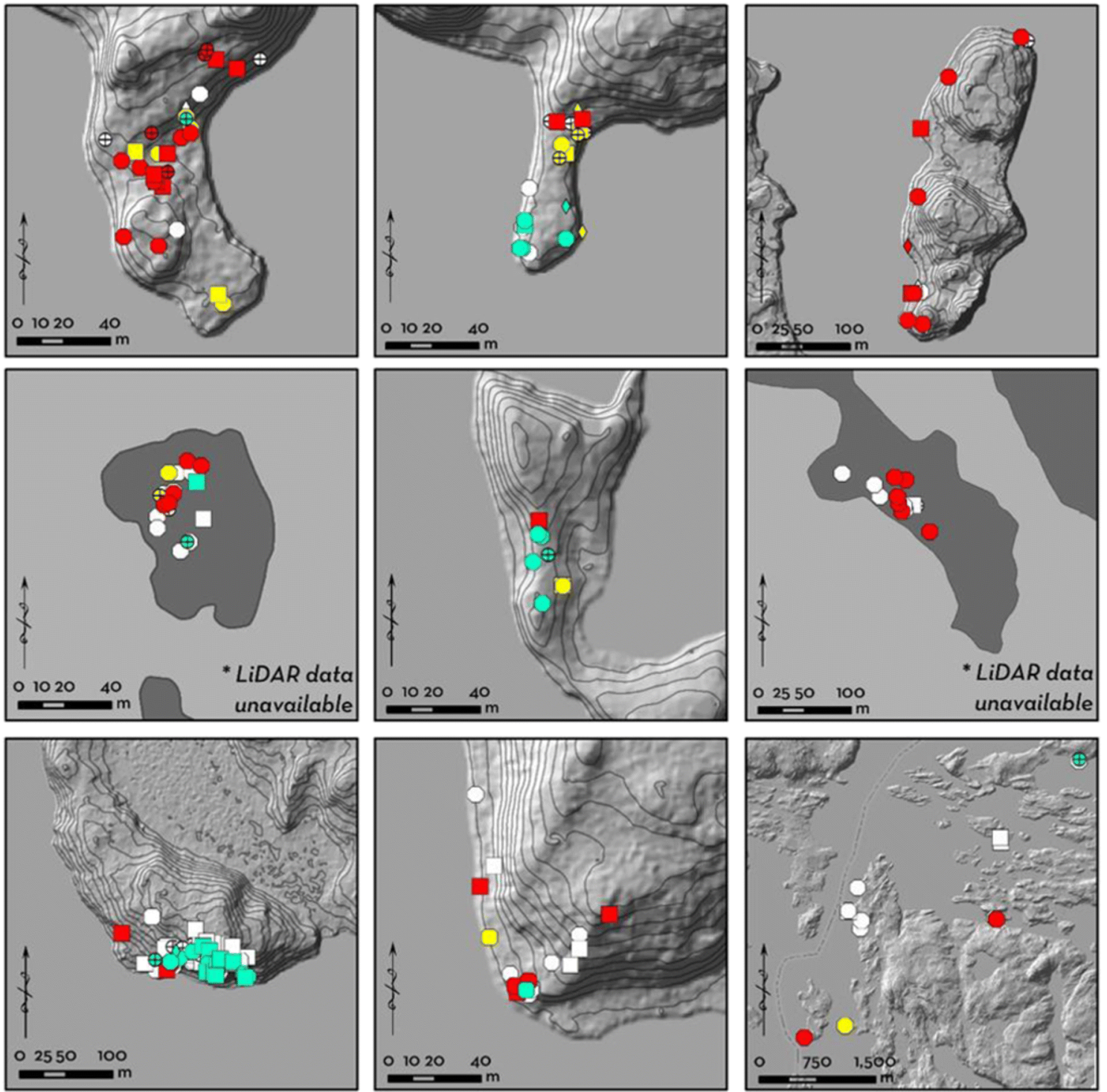

Fig. 9 Distribution of CMTs at nine sites with 2 or more CMTs. Colors denote time period of peel creation (aqua $=1700$ s, yellow $=1802-1822$, red $=$ after 1822 , white $=$ no tree-ring data for tree), while the symbol denotes the shape category of each peel $($ octagon $=$ oblong, square $=$ rectangular, diamond $=$ small/test, and crossed circle $=$ too decomposed to determine original shape). Digital elevation data retrieved from MNTOPO website (available: http://arcgis.dnr.state.mn.us/maps/ mntopo/, accessed July 3, 2018) and shown with 1-m contours

In 1783, the Treaty of Paris was signed between Great Britain and the United States of America (Treaty of Paris 1783). This peace treaty designated the Pigeon River, which makes up a large portion of the Border Route, as the northern border of the U.S. By 1800 the U.S. looked to impose customs on the British North West Company that still used Grand Portage, which was now located in the United States. In 1802 , the North West Company responded by moving its center of trade on the north shore of Lake Superior from Grand Portage to Fort William, present day Thunder Bay, Ontario, at the mouth of the Kaministiquia River (Innis 1999). This northward shift of the primary trade route away from the Border Route is recorded in the peel network as a reduction in fire and peel frequency for the next 19 years (1802-1821). During 

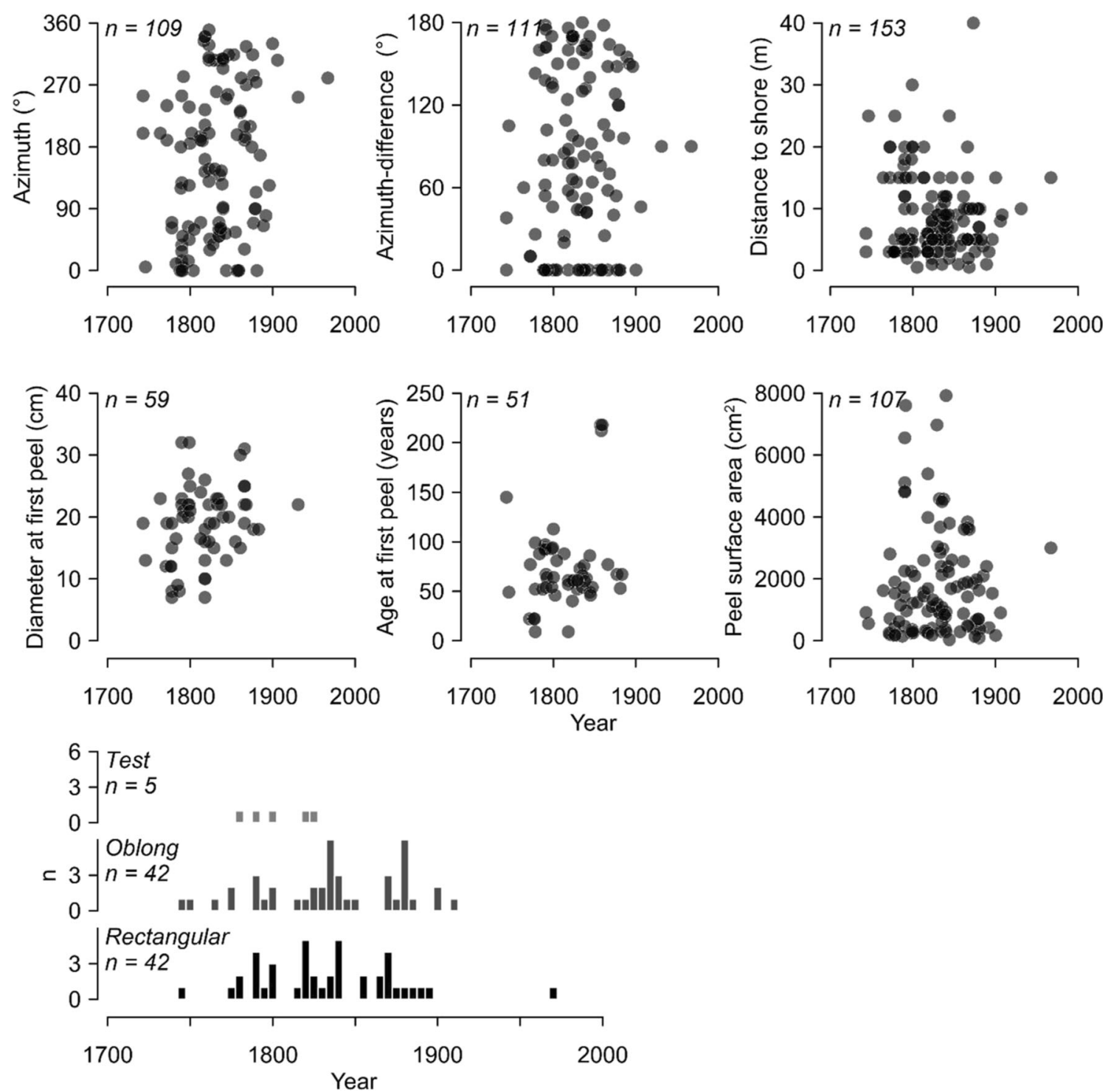

Fig. 10 Scatter plots relating the quantified peel characteristics with the date of creation, including azimuth of the peel face, difference in peel azimuth relative to the nearest shoreline, distance to the nearest shoreline, diameter of the tree at the date of the peel, age of the tree at the date of the peel, and the estimated surface area of the peel. A histogram at the bottom of the figure depicts the number of peels for each general type relative to the date of creation. The clear message from these visualizations is that peel characteristics were variable and mixed through time. these years, the Border Lakes fur trade followed the northern Kaministiquia Route rather than the Border Route. Peel activity resumed, albeit at a lesser intensity, with the merger of the Northwest Company and Hudson Bay Company in 1821 and associated renewed canoe traffic along the Border Route until the eventual decline of the fur trade in the mid- to late-1800s.

Treaties established between the U.S. government and numerous Indigenous groups from 1836 through 1889 ceded lands to the United States and established reservations across the region. In particular, the Treaty of 1854 , also known as the Treaty of La Pointe, ceded lands in northeastern Minnesota that include the area now considered the BWCAW (U.S. Congress 1854). Systematic attempts by the United States government to assimilate American Indians and disrupt
Indigenous cultures and traditional land use practices quickly followed the treaty making period. These efforts included, but were not limited to: strict regulations and fines against the intentional use of fire in resource management implemented in the 1890s and early 1900s (Andrews 1900: 7-8); the establishment of Indian boarding schools in the 1870s which included forcibly removing Indian children from their communities (Grover 2002); policies of fragmenting reservation lands though land allotments enacted through the federal Dawes Act of 1887 (U.S. Congress 1887); and the attempted removal of all Anishinaabeg in Minnesota who had not participated in allotment to the White Earth Reservation in western Minnesota as stipulated by the Nelson Act of 1889 (U.S. Congress 1889). Collectively, these and other practices 
dramatically diminished the presence of the Border Lakes Anishinaabeg and their traditional land use activities across the region, with clear links to the precipitous declines in peel and fire scars recorded in the CMT network by the end of the nineteenth century.

Despite efforts to suppress traditional subsistence activities within the Border Lakes, CMTs provide site-specific evidence of nearly two centuries of both concentrated and dispersed use of the landscape by the Anishinaabeg. Until recently, CMTs have been an unexplored archaeological resource in the Great Lakes region, yet these biological artifacts offer unparalleled spatiotemporal precision for exploring and better refining the archaeological record (Towner 2016) and ethnographic documentation of fur-trade-era Anishinaabeg land use.

The similarities in the frequency of peel scars and the frequency of fire scars recorded in the sampled CMTs is compelling and resonates with the key line of inquiry focused on identifying and quantifying the influence of people on historical fire regimes in protected areas around the world (Bowman et al. 2013). Continued documentation and data collection from CMTs in the Border Lakes will provide more interpretive power in assessing historical patterns of use relative to known sociopolitical events as well as further opportunities to relate CMT records to collocated fire history records, traditional knowledge, and oral histories.

\section{Enhancing the Archaeological Record}

Areas with high densities of CMTs are often indicators of the presence of undisturbed and data-rich subsurface archaeological deposits. Three notable CMT sites within the network, the Petit Rocher de Saginaga site complex (PRS) on Lake Saganaga, at South Coleman Island (SCI) on Lac La Croix, and on Upper Pauness Lake (UPL) serve as examples of the potential to use CMTs to refine understanding of previously studied cultural sites or identify previously unidentified archaeological sites. These sites either have a long record of human activity associated with them (PRS and UPL) or are newly recognized as sites with heavy cultural use (SCI). Both PRS and SCI are sites with dense concentrations of CMTs that are strategically located at critical points along the historic Border Route.

The broader PRS archaeological site complex is situated at a pinch point along the Border Route, on the east end of Lake Saganaga, through which almost all fur trade canoe traffic would have flowed. The CMTs at this location were previously interpreted as indicators of a multicultural site of mixed Indigenous and European influences, with evidence of strategic use by the Border Lakes Anishinaabeg in their adaptation to the fur trade economy (Johnson et al. 2018). From an archaeological standpoint, the PRS site complex appears to be one of the richest fur trade era archaeological sites currently documented within the BWCAW. Artifacts recovered from
United States Forest Service (USFS) investigations in 2009 2010 and artifacts recovered from the site by a private collector in the 1960s which were recently made available for analysis, indicate the site was heavily used by Border Lakes Anishinaabeg and passing Euro-American fur traders from approximately $1740-1870$ (Johnson et al. 2018). Historical accounts document Anishinaabe occupancy and canoe manufacturing activities at the site from the 1770 s to the 1820s (Henry 1809: 241; Bigsby 1850: 249-250; Coues 1965: 12-13). The site complex contained 30 CMTs, many of which were fire-killed in 2007, with modification dates in the 1840s that corroborate the archaeological record and extend the known period of use at this site beyond what the historical record suggested. CMT records associated with earlier Anishinaabe canoe manufacture and occupancy at this site complex were likely lost to wildfire. The trees present today at PRS would likely have been too small in diameter to utilize for pitch production in the early 1800 s but have been protected from high-severity fire over the past 200 years due to their island location and history of landuse.

South Coleman Island (SCI) is in the western BWCAW on Lac La Croix. It is at a point along the Border Route where two options for canoe travel exist: continue north bypassing SCI into the open waters of Lac La Croix or pass through a narrows in the lake $40 \mathrm{~m}$ wide into more protected waters. SCI was the largest and most intensely utilized site in the CMT network, suggestive that the choice offered by the landscape was recognized and leveraged by Anishinaabe groups participating in the fur trade. The cluster of $70 \mathrm{CMTs}$ recorded at the site are suggestive of a concerted 10-year effort in resin production coinciding with the height of the Border Route fur trade in the 1790s (Nute 1941) that aligns with a period when fires were also recorded across the site. A 20-year gap in occurrence of both fire and peels aligned with the shift of the fur trade to the Kaministiquia Route, and only three widespread fires were documented at the site in the subsequent half century. This illustrates links between changing cultural and ecological landscapes (Davidson-Hunt and Berkes 2003), with implications for understanding the drivers of ecological change in wilderness ecosystems (Larson et al. 2017).

USFS archaeologists worked to document the subsurface archaeological record at SCI during CMT collections in 2016. They performed a targeted survey of subsurface cultural materials with a metal detector and shovel tests in both an adjacent wilderness campsite and throughout a 1730s origin stand of lakeside, multi-aged red pine. Artifacts recovered suggest a multi-component site with three or four different periods of occupancy that are temporally and spatially distinct but also have peripheral overlap. Metal artifacts recovered are associated with late 1700s and early 1800s use of the Border Route and Anishinaabe interaction with traders connected with the British North West Company, including manufactured trade goods and ornamental items constructed from modified trade 
goods that are likely of Anishinaabe manufacture (USDA Forest Service 2017). Proximity of this site to the historical Anishinaabe community on the north side of Lac La Croix and the ca. 1780-1800 canoe route utilized by North West Company traders suggests that, like the PRS site complex, SCI was a strategic location at which Anishinaabe could engage in provisioning trade with passing canoe brigades. Most fur trade artifacts recovered were not located within the lakeside culturally-modified pine stand but on a raised terrace, in an old aspen (Populus tremuloides) patch with a thick hazel (Corylus cornuta) and mountain maple (Acer spicatum) understory. When the red pine at SCI were modified in the 1790 s, this aspen patch may have been a fire-maintained opening on flat ground, away from the lakeshore. It is unusual in the BWCAW to locate intact deposits of diagnostic fur trade period artifacts because archaeological surveys tend to only occur at wilderness campsites and portages, many of which have been impacted by recent visitor use. The CMTs at SCI served as indicators of a subsurface archaeological site of high data potential that would likely have remained unidentified in their absence.

The cluster of CMTs at UPL offers unique insight to relationships among Anishinaabe communities, traditional land use, and the landscape away from the areas most heavily influenced by the fur trade. Upper Pauness Lake is located along the Little Indian Sioux River, a waterway that served as a primary travel route between Anishinaabe communities at Lake Vermillion and Lac La Croix in the nineteenth and early twentieth century (Boshey Sr. 1996: 14). Modification dates among 10 dated peel scars range from 1802 to 1889 , with no single year recording more than one scar. The scale and timing of peel scars at UPL are more suggestive of individual use rather than large-scale resin production linked to the fur trade, and perhaps reflect customary stopping points and episodic canoe maintenance during the journey between communities influenced by the landscape itself. Artifacts recovered from the site during Forest Service archaeological surveys in the 1980s include transferware ceramics, kettle brass, and gun parts (USDA Forest Service 2017b). These artifacts corroborate the peel dates and support the notion of nineteenth century Anishinaabe use. The CMT cluster at UPL also provides context for interpreting other sites on the landscape that lack clear ethnographic, oral, or archaeological references. For example, Cummings Lake is the origin of the Little Indian Sioux River and far from the Border Route, yet a site where our fire history research identified a high likelihood of human-influenced fire regimes. The presence of two CMTs among the fire-scarred trees at Cummings Lake indicate human influences in the late 1700 s, while the dates of the fire events fall squarely within the period of peel activity documented on UPL. These results collectively illustrate a gradient of human influence across a network of sites and travel corridors that shifted through time (Miller and Davidson-Hunt 2010).

\section{Conclusions and Questions}

A network of 244 CMTs was developed that enhances our understanding of Anishinaabe use of the BWCAW landscape prior to 1900 . This network offers new information that may be used to assess the impact of Anishinaabeg land use on the forest mosaic of the Border Lakes and could serve as a catalyst for cross-cultural conversations on the stewardship of a federal wilderness area established on the ancestral lands of Indigenous peoples.

The network of CMTs reported here expands the representation of such records to a new region of the world and in doing so provides place- and time-specific links between people and place over centuries. In the BWCAW, CMT locations, densities, and dates, when merged with other tangible evidence of historical human use, can help archaeologists, ecologists, and historians better reconstruct and interpret landscapes of traditional movement (e.g., Snead et al. 2009). Historical portages, canoe routes, and associated archaeological sites can be studied as artifacts of human adaptation to landscapes, while CMTs may be viewed as nodes within historical travel networks that more clearly emerge as water-based travel corridors are retraced by "connecting the dots." For instance, a single CMT may be interpreted as opportunistic and short-duration use of a site by an individual or small group. Areas with high densities of CMTs indicate more strategic utilization of certain portions of travel routes, either due to repeat use over extended periods or through intensive use for a short time. This remapping of the Border Lakes cultural landscape may be used to refine existing knowledge of traditional Indigenous water trails, their transformation into fur-trade-era water routes, and their persistence on the landscape today. Through the examination of these cultural patterns of land use the agency of both landscapes and people will become more fully understood and appreciated.

From a broad perspective, trees are ephemeral fixtures on the landscape, and the CMTs documented here are a timelimited cultural resource. This study illustrates the urgency and importance of further research and collections in this region, as many of the CMTs sampled for this work were in advanced stages of decay. The more time that passes the more information is lost, and the story they can tell becomes more fragmented. As such, there is an urgency to catalog the distribution and ages of these trees across the greater Border Lakes landscape before these unique bio-cultural records are entirely lost. Additional CMT records may have gone undocumented along the Border Route due to a high-severity fire east of Lake Saganaga in 2007. In particular, the expansion of CMT documentation to the northern Kaministiqua trade route in Quetico Provincial Park will produce a more complete understanding of how land use shifted in response to changing political and economic conditions, and how these changes may have helped establish and maintain long-lived, multi-aged stands of red pine admired by wilderness visitors today. 
Acknowledgements This research was only possible with the support and efforts of a broad network of collaborators. Fieldwork was rigorous and could not have been completed without substantial efforts from Ben Matthys, Liz Schneider, Danica Larson, Ryan Brown, Heather Hoffman, Liam Martin, John Eads, Elizabeth Tanner, and Nicholas Harnish. The ideas and understanding that guided our approach to this research were shaped through numerous conversations with collaborators and stakeholders. Bill Latady provided valuable insight in the development of this project and facilitated conversations with members of the Bois Forte Band of Chippewa. Brian Jackson and Trevor Gibb invested in this process and helped us connect with members of the Lac La Croix First Nation. Conversations with Elders, council members, and knowledge carriers of the Bois Forte Band of Chippewa, Fond du Lac Band of Lake Superior Chippewa, and Lac La Croix First Nation guided our approaches to sampling and helped form our interpretations of the treering data. Sharing of stories and perspectives among the People, Fire, and Pines working group supported by the Coalition for Archaeological Synthesis (CfAS) shaped our interpretations of the data reported here, the implications derived for reconciling stewardship of the protected areas in the Border Lakes with the ever-growing understanding of the Border Lakes as a cultural landscape rather than a wilderness, and our approach to disseminating this work. Immense thanks to Jeff Savage, Jessica Atatise, and Robin Kimmerer for their collaboration in this effort. Finally, we wish to acknowledge that this work offers only a glimmer of the deep cultural heritage of the Border Lakes Region, and that the land in which we worked has seen the footsteps and paddles of many cultures, including Lakota, Assiniboine, Cree, and Anishinaabeg. To all those who have gone before, gichi-miigwech.

Data Availability Statement The datasets developed and analyzed during the current study are available from the corresponding author on reasonable request.

Funding Funding for this study was provided by National Science Foundation grants 1359868, 1359863, and 1560919, the Coalition for Archaeological Synthesis, and the USDA Forest Service.

\section{Compliance with Ethical Standards}

Conflict of Interest The authors declare that they have no conflict of interest.

Open Access This article is distributed under the terms of the Creative Commons Attribution 4.0 International License (http:// creativecommons.org/licenses/by/4.0/), which permits unrestricted use, distribution, and reproduction in any medium, provided you give appropriate credit to the original author(s) and the source, provide a link to the Creative Commons license, and indicate if changes were made.

\section{References}

Anderton, J. B. (1999). Native American, fire-maintained blueberry patches in the coastal pine forests of the northern Great Lakes. The Great Lakes Geographer 6: 29-39.

Andrews, C. C. (1900). Fifth annual report of the chief fire Warden of Minnesota for the year 1899, Pioneer Press Company, Saint Paul.

Bergman, I., Östlund, L., and Zackrisson, O. (2004). The use of plants as regular food in ancient subarctic economies: A case study based on Sami use of scots pine innerbark. Arctic Anthropology 41: 1-13.

Berkes, F. (2018). Sacred ecology, 4th edn., Routledge, Abingdon.
Berkes, F., and Davidson-Hunt, I. J. (2006). Biodiversity, traditional management systems, and cultural landscapes: Examples from the boreal forest of Canada. International Social Science Journal 58: 35-47.

Bigsby, J. J. (1850). The shoe and canoe; or pictures of travels in the Canadas, Chapman and Hall, London.

Birk, D. A. (1991). When rivers were roads: Deciphering the role of canoe portages in the western Lake Superior fur trade. Pages 359376 in the Fur trade revisited: Selected papers of the sixth north American Fur trade conference, Mackinac Island, Michigan. Michigan State University Press, Mackinac Island, Michigan.

Boshey Sr., J. (1996). The vermilion Lake people: Vermilion Lake bois forte Oral history project. Minnesota Historical Society, St. Paul, Minnesota. Digital transcription of oral interview accessed on-line 2018 at http://collections.mnhs.org/cms/display?irn=10469064.

Bowman, D. M. J. S., O'Brien, J. A., and Goldammer, J. G. (2013). Pyrogeography and the global quest for sustainable fire management. Annual Review of Environment and Resources 38: 57-80.

Child, B. 2014. My Grandfather's Knocking Sticks: Ojibwe Family Life and Labor on the Reservation. St. Paul, Minnesota: Minnesota Historical Society Press.

Coues, E. (ed.) (1965). New light on the early history of the greater northwest: The manuscript journals of Alexander Henry and of David Thompson, 1799-1814, 2nd edn., Francis P. Harper, New York.

Cronon, W. (1996). The trouble with wilderness; or, getting back to the wrong nature. In Cronon, W. (ed.), Uncommon ground: Rethinking the human place in nature, W.W. Norton \& Company, Inc., New York, pp. 69-90.

Davidson-Hunt, I. (2003). Indigenous lands management, cultural landscapes and Anishinaabe people of shoal Lake, northwestern Ontario, Canada. Environments 31: 22-41.

Davidson-Hunt, A., and Berkes, F. (2003). Learning as you journey: Anishinaabe perception of social-ecological environments and adaptive learning. Conservation Ecology 8: 5.

Denevan, W. M. (1992). The pristine myth: The landscape of the Americas in 1492. Annals of the Association of American Geographers 82: 369-385.

Denevan, W. M. (2011). The "pristine myth" revisited. Geographical Review 101: 576-591.

Densmore, F. (1929). Chippewa customs, Smithsonian Institute, Washington, D.C.

Díaz, S., Demissew, S., Carabias, J., Joly, C., Lonsdale, M., Ash, N., Larigauderie, A., Adhikari, J. R., Arico, S., Báldi, A., Bartuska, A., Baste, I. A., Bilgin, A., Brondizio, E., Chan, K. M. A., Figueroa, V. E., Duraiappah, A., Fischer, M., Hill, R., Koetz, T., Leadley, P., Lyver, P., Mace, G. M., Martin-Lopez, B., Okumura, M., Pacheco, D., Pascual, U., Pérez, E. S., Reyers, B., Roth, E., Saito, O., Scholes, R. J., Sharma, N., Tallis, H., Thaman, R., Watson, R., Yahara, T., Hamid, Z. A., Akosim, C., Al-Hafedh, Y., Allahverdiyev, R., Amankwah, E., Asah, S. T., Asfaw, Z., Bartus, G., Brooks, L. A., Caillaux, J., Dalle, G., Darnaedi, D., Driver, A., Erpul, G., Escobar-Eyzaguirre, P., Failler, P., Fouda, A. M. M., Fu, B., Gundimeda, H., Hashimoto, S., Homer, F., Lavorel, S., Lichtenstein, G., Mala, W. A., Mandivenyi, W., Matczak, P., Mbizvo, C., Mehrdadi, M., Metzger, J. P., Mikissa, J. B., Moller, H., Mooney, H. A., Mumby, P., Nagendra, H., Nesshover, C., Oteng-Yeboah, A. A., Pataki, G., Roué, M., Rubis, J., Schultz, M., Smith, P., Sumaila, R., Takeuchi, K., Thomas, S., Verma, M., YeoChang, Y., and Zlatanova, D. (2015). The IPBES conceptual framework - Connecting nature and people. Current Opinion in Environmental Sustainability 14: 1-16.

Frelich, L. E. (2002). Forest dynamics and disturbance regimes, Cambridge University Press, Cambridge.

Frissell, S. S., and Duncan, D. P. (1965). Campsite preference and deterioration in the Quetico-superior canoe country. Journal of Forestry 63: $256-260$. 
Grover, L. L. (2002). From assimilation to termination: The Vermilion Lake Indian school. Minnesota History 58: 224-240.

Harwood, C., and Ruuska, A. K. (2013). The personhood of trees: Living artifacts in the upper peninsula of Michigan. Time and Mind 6: 135157.

Heinselman, M. L. (1973). Fire in the virgin forests of the boundary waters canoe area, Minnesota. Quaternary Research 3: 329-382.

Heinselman, M. L. (1996). The boundary waters wilderness ecosystem, University of Minnesota Press, Minneapolis.

Henry, A. (1809). Travels and adventures in Canada and the Indian territories, between the years 1760 and 1776: In two parts, T. Riley, New York.

Innis, H. (1999). The Fur trade in Canada: An introduction to Canadian economic history, University of Toronto Press, Toronto.

Johnson, L. R. (2009). Assessing the effects of anthroturbation on an initial woodland site in the boundary waters canoe area wilderness. The Minnesota Archaeologist 68: 71-92.

Johnson, L. B., and Kipfmueller, K. F. (2016). A fire history derived from Pinus resinosa Ait. For the islands of eastern lac La Croix, Minnesota, USA. Ecological Applications 26: 1030-1046.

Johnson, L. B., Johnson, L., Larson, E. R., and Kipfmueller, K. F. (2018). Culturally-modified red pine, birch-bark canoes, and the fur trade on Lake Saganaga, Minnesota, USA. Historical Archaeology 52: 281300 .

Kimmerer, R. W. 2014. Braiding Sweetgrass: Indigenous Wisdom, Scientific Knowledge, and the Teachings of Plants. Minneapolis, Minnesota: Milkweed Editions.

Kipfmueller, K. F., Elliott, G. P., Larson, E. R., and Salzer, M. W. (2010). An assessment of the dendroclimatic characteristics of three conifer species in northern Minnesota. Tree-Ring Research 66: 113-126.

Kipfmueller, K. F., Schneider, E. A., Weyenberg, S. A., and Johnson, L. B. (2017). Historical drivers of a frequent fire regime in the red pine forests of voyageurs National Park, MN, USA. Forest Ecology and Management 405: 31-43.

Larson, E. R., Johnson, L. B., and Kipfmueller, K. F. (2017). What is Wilderness? Examining tree rings, researchers consider the history of human influence in the Boundary Waters. Minnesota Conservation Volunteer 80: 22-30.

Lewis, H. T., and Ferguson, T. A. (1988). Yards, corridors, and mosaics: How to burn a boreal forest. Human Ecology 16: 57-77.

Miller, A. M., and Davidson-Hunt, I. (2010). Fire, agency and scale in the creation of aboriginal cultural landscapes. Human Ecology 38: 401414.

Miller, A. M., Davidson-Hunt, I. J., and Peters, P. (2010). Talking about fire: Pikangikum first nation elders guiding fire management. Canadian Journal of Forest Research 40: 2290-2301.

Mobley, C. M., and Eldridge, M. (1992). Culturally modified trees in the Pacific northwest. Arctic Anthropology 29: 91-110.

Morrison, M., and Shepard, E. (2013). The archaeology of culturally modified trees: Indigenous economic diversification within colonial intercultural settings in Cape York peninsula, northeastern Australia. Journal of Field Archaeology 38: 143-160.

Morse, E. W. (1962). Canoe routes of the voyageurs: The geography and logistics of the Canadian Fur trade, Minnesota Historical Society, St. Paul.

Morse, E. W. (1969). Fur trade canoe routes/ then and now, Queen's Printer, Ottawa.

Mulholland, S. C., Mulholland, S. L., Peters, G. R., Huber, J. K., and Mooers, H. D. (1997). Paleo-Indian occupations in northeastern Minnesota: How early? North American Archaeologist 18: 371400.

Nute, G. L. (1941). The Voyageur's highway: Minnesota's border Lake land, Minnesota Historical Society Press, St. Paul.

Östlund, L., and Bergman, I. (2006). Cultural landscapes in northern forests - time, space and affiliation to the land. In Agnoletti, M. (ed.), Conservation of cultural landscapes, CAB International, Oxfordshire, pp. 30-41.

Östlund, L., Zackrisson, O., and Hornberg, G. (2002). Trees on the border between nature and culture - culturally modified trees in boreal Sweden. Environmental History 7: 48-68.

Östlund, L., Keane, B., Arno, S., and Andersson, R. (2005). Culturally scarred trees in the bob Marshall wilderness, Montana, USA - interpreting native American historical forest use in a wilderness area. Natural Areas Journal 25: 315325.

Östlund, L., Bergman, I., and Zackrisson, O. (2015). Trees for food - A 3000 year record of subarctic plant use. Antiquity 78: 278-286.

Richner, J. (2002). People of the thick fur woods: Two hundred years of bois forte Chippewa occupation of the voyageurs National Park area, U.S. Dept. of the Interior, National Park Service, Midwest Archeological Center.

Roosevelt, T. (1909). Proclamation no. 848, Washington, D.C.

Rudolf, P. O. (1990). Pinus resinosa Ait: Red pine. In Burns, R. M., and Honkala, B. H. (eds.), Silvics of North America: 1. Conifers, U.S. Department of Agriculture, Forest Service, agricultural handbook 654, Ogden, pp. 900-929.

Ryden, K. C. (1993). Mapping the invisible landscape: Folklore, writing, and the sense of place, University of Iowa Press, Iowa City.

Samojlik, T., Fedotova, A., Niechoda, T., and Rotherham, I. D. (2019). Culturally modified trees or wasted timber: Different approaches to marked trees in Poland's Białowieża Forest. PLoS One 14: e0211025.

Snead, J. E., Erickson, C. L., and Darling, J. A. (2009). Landscapes of movement: Trails, paths, and roads in anthropological perspective, University of Pennsylvania Press, Philadelphia.

Stewart, O. C. (2002). Forgotten fires: Native Americans and the transient wilderness, University of Oklahoma Press, Norman.

Stokes, M. A., and Smiley, T. L. (1996). An introduction to tree-ring dating, University of Arizona Press, Tucson.

Swetnam, T. W. (1984). Peeled ponderosa pine trees: A record of inner bark utilization by native Americans. Journal of Ethnobiology 4: $177-190$

Tengö, M., Hill, R., Malmer, P., Raymond, C. M., Spierenburg, M., Danielsen, F., Elmqvist, T., and Folke, C. (2017). Weaving knowledge systems in IPBES, CBD and beyond-Lessons learned for sustainability. Current Opinion in Environmental Sustainability 26-27: 17-25.

Towner, R. H. (2016). Arboreal archaeology and early Navajo land use. Journal of Archaeological Science: Reports 6: 342-350.

Treaty of Paris. (1783). International Treaties and Related Records, 1778 1974. National Archives, General Records of the United States Government, Record Group 11.

Treuer, A. (2010). Ojibwe in Minnesota, Minnesota Historical Society Press, St. Paul.

Turner, N. J., Ari, Y., Berkes, F., Davidson-Hunt, I., Ertug, Z. F., and Miller, A. (2009). Cultural management of living trees: An international perspective. Journal of Ethnobiology 29: 237-270.

U.S. Congress. (1854). Treaty with the Chippewa, 1854 (second treaty of La pointe). Pages 10 stats., 1109 in C. J. Kappler, editor. Indian affairs: Laws and Treaties. Government printing office, 1904, Washington, D.C.

U.S. Congress (1887). An act to provide for the allotment of lands in severalty to Indians on the various reservations (general allotment act or Dawes act). Statutes at Large 24: 388-391 NADP document A1887.

U.S. Congress (1889). An act for the relief and civilization of the Chippewa Indians in the state of Minnesota (Nelson act). Executive Document 247: 642-646 NADP document A1889.

U.S. Congress. (1964). AN ACT: To establish a National Wilderness Preservation System for the permanent good of the whole people, 
and for other purposes (wilderness act).in S. s. 88th Congress, editor. Public law 88-577 (16 U.S. C. 1131-1136). 88th Congress, second session.

U.S. Congress. (1978). AN ACT: To designate the boundary waters canoe area wilderness, to establish the boundary waters canoe area mining protection area, and for other purposes (boundary waters canoe area wilderness ACT). Public law 95-495 (92 stat. 1649). 95th Congress.

USDA Forest Service (2017). Cultural resource inventory form \#09-0906-535, Superior National Forest Supervisors Office, Duluth.

USDA Forest Service (2017b). Cultural resource inventory form \#09-0906-206, Superior National Forest, Supervisors Office, Duluth.

Vale, T. R. (1998). The myth of the humanized landscape: An example from Yosemite National Park. Natural Areas Journal 18: 231-236.
Vale, T. R. (2002). The pre-European landscape of the United States: Pristine or humanized? In Vale, T. R. (ed.), Fire, native peoples, and the natural landscape, Island Press, Washington, D.C., pp. 1-40.

Warren, W. W. (2009). History of the Ojibway people, 2nd edn., The Minnesota Historical Society Press, Saint Paul.

Zackrisson, O., Ostlund, L., Korhonen, O., and Bergman, I. (2000). The ancient use of Pinus sylvestris L. (scots pine) inner bark by Sami people in northern Sweden, related to cultural and ecological factors. Vegetation History and Archaeobotany 9: 99-109.

Publisher's Note Springer Nature remains neutral with regard to jurisdictional claims in published maps and institutional affiliations. 